\title{
The Mechanism of Decreased Serum Phosphorus Levels in Rats with Chronic Kidney Disease after Oral Administration of Bifidobacterium longum
}

\author{
Nobuo Nagano ${ }^{1,2 *}$, Mayuko Futaya ${ }^{2}$, Mamiko Kohno ${ }^{3}$, Osami Nakano ${ }^{3}$, Norihisa Nishida ${ }^{3}$, \\ Yoichi Matsuura ${ }^{3}$, Mikiko Shimada', Kyoko Ito' ${ }^{1}$, Tetsuo Ando', Takaaki Tsutsui', \\ Yoshitaka Ando', Kiyotsugu Omae ${ }^{4}$, Kosaku Nitta ${ }^{5}$, Hiroshi Sakura², Tetsuya Ogawa ${ }^{2}$ \\ ${ }^{1}$ Kidney Disease and Dialysis Center, Hidaka-kai, Takasaki, Gunma, Japan \\ ${ }^{2}$ Department of Medicine, Tokyo Women's Medical University Medical Center East, Tokyo, Japan \\ ${ }^{3}$ Research and Development Division, Morishita Jintan Co., Ltd., Osaka, Japan \\ ${ }^{4}$ Department of Internal Medicine, Yoshikawa Clinic, Tokyo, Japan \\ ${ }^{5}$ Department of Medicine, Kidney Center, Tokyo Women's Medical University, Tokyo, Japan \\ Email: ${ }^{*}$ n_nagano@hidaka-kai.com
}

Received 30 June 2015; accepted 19 July 2015; published 22 July 2015

Copyright (C) 2015 by authors and Scientific Research Publishing Inc.

This work is licensed under the Creative Commons Attribution International License (CC BY). http://creativecommons.org/licenses/by/4.0/

(c) (i) Open Access

\section{Abstract}

Chronic kidney disease (CKD) patients are prone to disturbances in the intestinal microbiota, which contributes to CKD progression and complications. We previously reported a reduction of serum phosphorus (P) levels in hemodialysis patients receiving oral encapsulated bifidobacteria. The present study was conducted to clarify the mechanisms of P-lowering effect of bifidobacteria on CKD rats. CKD was induced in rats by 5/6 nephrectomy. Five weeks later, the rats were fed for 4 weeks on a powder diet containing encapsulated bifidobacteria. At the end of the study, intestinal contents were sampled for analyses of $\mathrm{pH}$, intestinal flora and short-chain fatty acids (SCFAs). Oral administration of bifidobacteria halted the onset and progression of hyperphosphatemia in CKD rats. The increased number of bifidobacteria was confirmed in the cecum. In addition, the increase in intestinal $\mathrm{pH}$ in CKD rats was decreased after bifidobacteria treatment, along with increases in some SCFAs. Furthermore, positive correlation between serum $P$ levels and intestinal $\mathrm{pH}$ was observed. In conclusion, the mechanism for the P-lowering effect of bifidobacteria was supposed as follows: CKD conditions increase aerobic bacteria which hydrolyze urea into ammonia. Elevated pH decreases ionization of intestinal calcium (Ca) which leads to an increase in free phosphate ions through reduction of $\mathrm{Ca}$ phosphate crystal precipitation. Administered bifidobacteria fer-

\footnotetext{
${ }^{*}$ Corresponding author.
}

How to cite this paper: Nagano, N., et al. (2015) The Mechanism of Decreased Serum Phosphorus Levels in Rats with Chronic Kidney Disease after Oral Administration of Bifidobacterium longum. Advances in Microbiology, 5, 531-540. 
mented carbohydrates to produce SCFAs, resulting in acidification of the intestinal lumen. The resulting low intestinal pH increases Ca ionization, which binds with free phosphate ions as an intrinsic $P$ binder, resulting in the reduction of serum $P$ levels.

\section{Keywords}

Bifidobacteria, CKD-MBD, Dysbiosis, Hyperphosphatemia, Intestinal pH, Short-Chain Fatty Acids

\section{Introduction}

Recent basic and clinical findings have demonstrated that altered intestinal microbiota (dysbiosis) was associated with metabolic diseases, including obesity, diabetes, atherosclerosis and fatty liver disease [1] [2]. Chronic kidney disease (CKD) patients are prone to have dysbiosis because of many factors such as urea overload, decreased consumption of dietary fiber, frequent use of antibiotics and phosphate binders, prolonged colonic transit and constipation [3] [4]. Indeed, profound dysbiosis has been observed in both peritoneal dialysis (PD) and hemodialysis (HD) patients [5]-[7]; it is considered that uremic toxins and putrefactive substances that originate from this process may contribute to the deterioration of renal function, systemic inflammation, immunosuppression, cardiovascular calcification, metabolic bone disease and mortality in CKD patients [3] [4] [8] [9].

Bifidobacterium is a non-motile, Gram-positive, anaerobic prokaryote that inhabits the gastrointestinal tract. To date, more than 30 species have been isolated from humans and animals [10]. They can biosynthesize various substances such as amino acids, purines, pyrimidines, short-chain fatty acids (SCFAs), vitamins $\mathrm{B}_{1}, \mathrm{~B}_{6}, \mathrm{~B}_{12}, \mathrm{~K}$ and folate [4] [10]. Therefore, bifidobacteria possess various potential health benefits to humans, including prevention of diarrhea, alleviation of constipation, treatment of inflammatory bowel disease, immunomodulation, cholesterol reduction, improvement of lactose intolerance and prevention of cancer [10] [11]. However, a significantly lower number of bifidobacteria have been reported in the feces of HD and PD patients [5] [6].

Bifidobacteria, when administered orally, cannot survive exposure to gastric juice before they reach the intestine. In order to reach the intestine, bifidobacteria can be placed in a gastro-resistant seamless capsule in the form of human Bifidobacterium longum JBL01 (B-HD capsule, Morishita Jintan Co., Ltd., Japan), to enable it to survive even in a solution with $\mathrm{pH}$ of 1.2 for $120 \mathrm{~min}$ [12]. Without the capsule (i.e. in powder formulation), bifidobacteria cannot be detected immediately after mixing with the solution. We administered B-HD capsules to our HD patients for 4 weeks in order to improve dysbiosis and fecal impaction [13]. In the study, significant reduction of serum phosphorus (P) levels was unexpectedly observed only during B-HD capsule administration [13]. The mechanism for the P-lowering effect of bifidobacteria has been uncertain, although it is presumed to be due to its decreasing effect on intestinal $\mathrm{pH}$ via SCFAs production. Therefore, the present study was conducted to clarify the mechanism for this P-lowering effect of B-HD capsule using 5/6 nephrectomized rats in which dysbiosis was also recognized [7].

\section{Materials and Methods}

\subsection{Experimental Protocol}

The procedure was approved by the Experimental Animal Ethical Committee of Tokyo Women's Medical University. Male Wistar rats (7 weeks of age, Japan SLC Inc.) were subjected to 5/6 partial nephrectomy (Nx) in a two-step surgery as previously reported [14]. Six normal rats were used as control. Each rat was kept singly in cages and allowed free access to standard powder diet (Ca 1.08\%, P 1.07\%; CE-2, CLEA Japan) and water. After an acclimatization period of 5 weeks, blood sample was collected from a tail artery to measure serum creatinine (Cr), blood urea nitrogen (BUN), calcium (Ca) and P levels. Nx rats were divided into two groups of eight rats which were matched by body weight. One group $(\mathrm{Nx}+$ placebo) was fed on a standard powder diet containing 6.3\% seamless capsule that included potato starch (placebo capsule, Morishita Jintan Co., Ltd., Japan) with $0.012 \%$ lactulose and $0.0031 \%$ raffinose for 4 weeks. Control rats (control group) were fed on the same diet. The other group ( $\mathrm{Nx}+\mathrm{B}-\mathrm{HD})$ was fed on a standard powder diet containing $6.3 \% \mathrm{~B}-\mathrm{HD}$ capsule $\left(1.2 \times 10^{8}\right.$ $\mathrm{CFU} / \mathrm{g}$ of Bifidobacterium longum JBL01) with the same amount of oligosaccharides for 4 weeks. We set the 
same administration period (for 4 weeks) as our study on HD patients [13]. The number of Bifidobacterium was determined according to a previous study that used encapsulated Bifidobacterium breve on rats [15]. The proportion of oligosaccharide to Bifidobacterium was same as in our human study. Since the average food intake of the $\mathrm{Nx}+\mathrm{B}-\mathrm{HD}$ group was $14.3 \mathrm{~g} /$ day for 4 weeks, the amount of daily Bifidobacterium longum intake was calculated to be at $1.08 \times 10^{8} \mathrm{CFU} / \mathrm{rat}$. Body weight and volume of food intake were measured and blood sample was collected from the tail artery to measure serum chemistries every week.

Three rats in the $\mathrm{Nx}+$ placebo group developed severe illness due to azotemia between 3 and 4 weeks after feeding treatment was started. Therefore, we collected blood sample and a small part of intestinal contents to measure $\mathrm{pH}$ and SCFAs, and then sacrificed the rats before the end of the study.

Four weeks after initiation of feeding treatment, $24 \mathrm{~h}$ urine and feces samples were collected with metabolic cages, after which the rats were sacrificed under isoflurane inhalation anesthesia. The rats were immediately dissected and the contents of the jejunum, ileum and cecum were collected because the jejunum and ileum are the main sites of intestinal $\mathrm{P}$ absorption and cecal content is frequently used for analyses of SCFAs and microbiome in rats. A small portion of intestinal contents was assigned to $\mathrm{pH}$ measurement and the rest of the cecal contents were immediately frozen in liquid nitrogen until measurement of SCFAs and microbiome analysis.

\subsection{Serum and Urinary Chemistries, pH and Fecal Weight}

Serum Ca, P, BUN and Cr and urine protein and Cr were measured by the usual method at MONOLIS Co., Ltd. (Japan). Cr clearance (CCr) was calculated from a standard formula. After sampling, the $\mathrm{pH}$ of intestinal contents was immediately measured with a handy digital pH meter (KS701, Shindengen Electric Manufacturing Co., Ltd. Japan). Wet feces were dried in an incubator at $70^{\circ} \mathrm{C}$ and then measured as fecal dry weight.

\subsection{S rRNA Gene Sequence Analysis for Intestinal Flora}

All procedures were conducted at Primary cell division of Cosmo Bio Co Ltd. (Japan). Frozen cecal contents were dried and powdered before subjecting to DNA extraction using the QIAamp DNA Stool Mini Kit (Qiagen, Netherlands). The concentrations of DNA extract solutions were determined using a spectrophotometer. DNA solutions were diluted 100 -fold for all test bacteria and Lactobacillus and 10-fold for the other targets. According to a previous report, quantitative real-time polymerase chain reaction (PCR) using Light Cycler 480 SYBR Green I Master (Roche Diagnostics K.K., Japan) was performed with 16S rRNA gene-targeted, group-specific primers for all bacteria, Bacteroides, Prevotella, Lactobacillus, Streptococcus, Clostridium coccoides, Clostridium leptum and Bifidobacterium [16]. The PCR primers used in the present study were the same as those previously reported [17]-[19]. The relative ratio of each test bacteria to all bacteria (\%) was calculated.

\subsection{Measurement of Short-Chain Fatty Acids}

Cecal contents were sterilized at $80^{\circ} \mathrm{C}$ for 15 min with an extracting solvent and then smashed. After centrifugation at 13,000 rpm for $10 \mathrm{~min}$, the supernatant fluid was passed through a $0.45 \mu \mathrm{m}$ membrane filter and assigned for measurement of nine kinds of SCFAs (succinic acid, lactic acid, formic acid, acetic acid, propionic acid, iso-butyric acid, n-butyric acid, iso-valeric acid and n-valeric acid) by high performance liquid chromatography (HPLC) at Techno Suruga Laboratory Co., Ltd. (Japan). The amounts of formic acid, iso-butyric acid and n-valeric acid were either under the limit of quantification (LOQ) or the same in almost all samples; thus, they were excluded from the analysis. For the other SCFAs, samples under the LOQ were calculated as $0 \mathrm{mg} / \mathrm{g}$.

\subsection{Statistical Analysis}

All values were expressed as mean \pm SEM. Shapiro-Wilk test was used to test for normality. Two groups were compared with Student's t-test and Mann-Whitney U test for normal and non-normal distribution of data, respectively. Multiple comparisons were performed by ANOVA along with post-hoc Tukey test or Kruskal-Wallis test followed by Bonferroni correction. Serum P levels at 4 weeks were also compared between two Nx groups using Mann-Whitney U test. Correlation analyses were performed using Spearman's correlation test. A level of $\mathrm{P}<0.05$ was considered statistically significant. Analyses were performed using IBM SPSS Statistics (version 21) for Windows. 


\section{Results}

\subsection{Body Weight and Food Intake}

Throughout the study, body weight was lower in the groups $\mathrm{Nx}+$ placebo and Nx + B-HD than that in the control group (Figure 1(a)). The three rats in the $\mathrm{Nx}+$ placebo groups that needed to be euthanized had stunted body weight gain. On the contrary, body weight steadily increased in the $\mathrm{Nx}+\mathrm{B}-\mathrm{HD}$ group. Mean food intake volume (g/rat/day) was $18.1 \pm 0.26$ for the control, $14.7 \pm 0.45$ for $\mathrm{Nx}+$ placebo and $14.3 \pm 0.51$ for $\mathrm{Nx}+$ B-HD.

\subsection{Serum Chemistries}

Serum $\mathrm{Cr}$ and BUN levels gradually increased in the $\mathrm{Nx}+$ placebo group but were within normal range in the control group (Figure 1(b), Figure 1(c)). B-HD treatment appeared to inhibit the elevation of serum Cr and BUN levels but the differences between $\mathrm{Nx}+$ placebo and B-HD were not statistically significant except Cr at 1 week. At 4 weeks, significant elevations of serum $\mathrm{Cr}$ and BUN were observed in Nx + placebo, whereas no significant difference was observed in $\mathrm{Nx}+\mathrm{B}-\mathrm{HD}$, compared with those in control rats. Serum Ca levels gradually decreased in $\mathrm{Nx}+$ placebo and significant reductions were observed at 2 and 3 weeks when compared with the control (Figure 1(d)). In contrast, serum Ca levels in $\mathrm{Nx}+\mathrm{B}-\mathrm{HD}$ did not show any significant reduction throughout the study.

Serum P levels progressively increased in $\mathrm{Nx}+$ placebo later on in the study period (Figure 2). B-HD treatment inhibited occurrence and progression of hyperphosphatemia and maintained serum $\mathrm{P}$ levels similar with the control. Statistical difference was observed between $\mathrm{Nx}+$ placebo and $\mathrm{Nx}+\mathrm{B}-\mathrm{HD}$ at 4 weeks. There was not a significant difference between $\mathrm{Nx}+\mathrm{B}-\mathrm{HD}$ and control at any point throughout the study.

\subsection{Renal Function and Fecal Weight}

Urine volume (mL/rat/day) markedly increased in $\mathrm{Nx}+$ placebo $(44.9 \pm 2.45)$ and $\mathrm{Nx}+\mathrm{B}-\mathrm{HD}(43.0 \pm 3.30)$
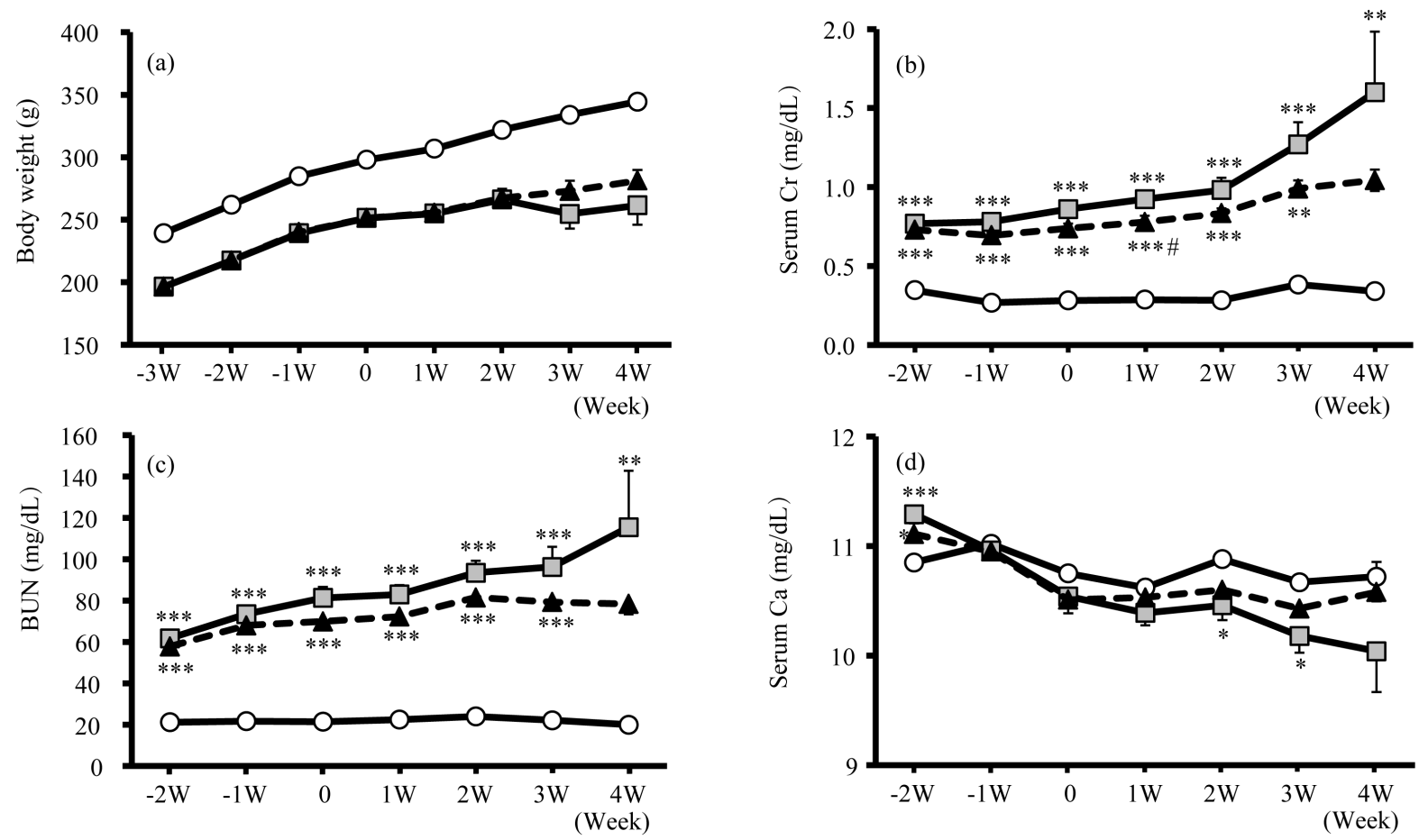

Figure 1. Effects of B-HD treatment on body weight (a), serum $\mathrm{Cr}$ (b), BUN (c) and Ca (d) levels in CKD rats. Control: open circles. $\mathrm{Nx}+$ placebo: gray square; $\mathrm{Nx}+\mathrm{B}-\mathrm{HD}$ : filled triangle. ${ }^{*} \mathrm{P}<0.05,{ }^{* * *} \mathrm{P}<0.01,{ }^{* * * *} \mathrm{P}<0.001$ vs Control. ${ }^{\#} \mathrm{P}<0.05$ vs $\mathrm{Nx}+$ placebo. The statistical differences $\left({ }^{* * *} \mathrm{P}<0.001\right)$ were observed in $\mathrm{Nx}+$ placebo and $\mathrm{Nx}+\mathrm{B}-\mathrm{HD}$ at all points but asterisks were not indicated in Figure 1(a). 


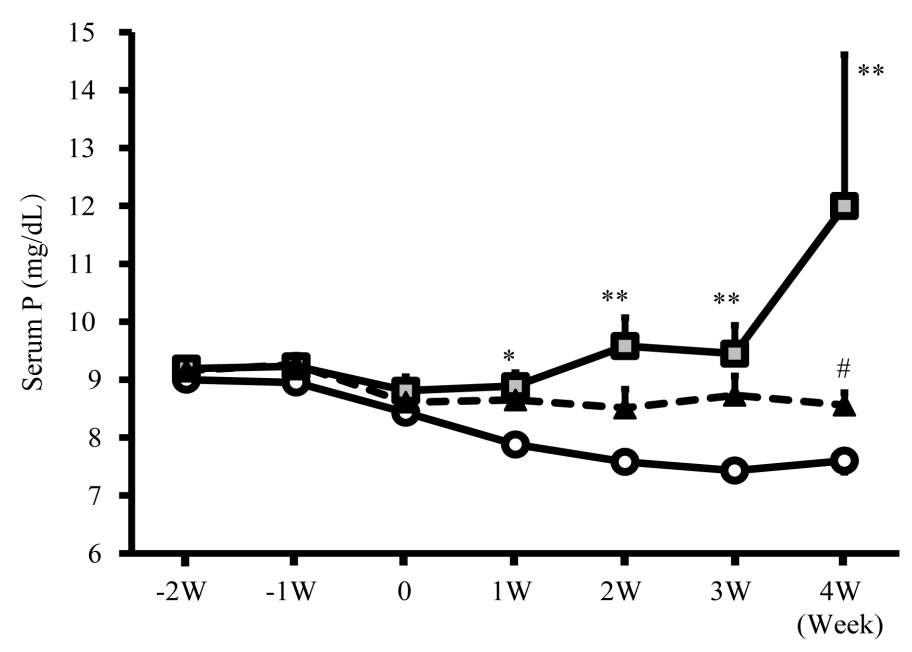

Figure 2. Effects of B-HD treatment on serum $\mathrm{P}$ levels in CKD rats. Control: open circles. $\mathrm{Nx}+$ placebo: gray square; $\mathrm{Nx}+\mathrm{B}-\mathrm{HD}$ : filled triangle. ${ }^{*} \mathrm{P}<0.05,{ }^{* *} \mathrm{P}<0.01$ vs Control. ${ }^{\#} \mathrm{P}<0.05$ vs $\mathrm{Nx}+$ placebo.

compared with that in the control (10.0 \pm 0.28$)$. Similarly, marked proteinuria (mg/rat/day) was observed in $\mathrm{Nx}$ + placebo (215.7 \pm 60.9) and Nx + B-HD (223.1 \pm 38.1); urine protein was within the normal range in the control $(6.1 \pm 0.14)$. CCr $(\mathrm{mL} / \mathrm{min})$ decreased in $\mathrm{Nx}+$ placebo $(0.64 \pm 0.13)$ and $\mathrm{Nx}+\mathrm{B}-\mathrm{HD}(0.81 \pm 0.06)$ compared with that in the control $(2.66 \pm 0.23)$. Statistical significances were observed in all three parameters when the control was compared with $\mathrm{Nx}+$ placebo or $\mathrm{Nx}+\mathrm{B}-\mathrm{HD}$, but there was no significant difference between $\mathrm{Nx}$ + placebo and $\mathrm{Nx}+\mathrm{B}-\mathrm{HD}$. Fecal dry weight (g/rat/day) showed no significant difference among three groups: control, $2.09 \pm 0.27 ; \mathrm{Nx}+$ placebo, $2.37 \pm 0.16$ and $\mathrm{Nx}+\mathrm{B}-\mathrm{HD}, 2.31 \pm 0.18$.

\subsection{Intestinal $\mathrm{pH}$ and Serum $\mathrm{P}$ Levels}

The $\mathrm{pH}$ of the jejunal and ileal contents in $\mathrm{Nx}+\mathrm{B}-\mathrm{HD}$ was significantly higher than that of the control (Figure $3)$. The $\mathrm{pH}$ in the cecum was also increased but statistical difference was not observed. B-HD treatment showed a tendency to decrease $\mathrm{pH}$ levels in the jejunum and cecum but did not show statistical significance between $\mathrm{Nx}$ + placebo and $\mathrm{Nx}+\mathrm{B}-\mathrm{HD}$.

Analysis of all normal and Nx rats showed significant and positive correlation of serum $\mathrm{P}$ level with $\mathrm{pH}$ of contents in the jejunum $(r=0.461, P=0.041)$ and cecum $(r=0.524, P=0.015)$. In contrast, significant correlation was not observed between serum $\mathrm{P}$ level and $\mathrm{pH}$ of ileum content $(\mathrm{r}=0.295, \mathrm{P}=0.183)$.

\subsection{Intestinal Microbiota}

The relative ratio (\%) of each of the seven bacterial genera to all bacteria is shown in Table 1. As previously reported, the bacterial counts of Prevotella and Streptococcus genera were low and those of Bacteroides and Bifidobacterium genera were extremely low [16]. Control and $\mathrm{Nx}+$ placebo had no statistical difference in all seven bacterial genera. On the contrary, compared with $\mathrm{Nx}+$ placebo, B-HD treatment tended to increase the putative copy number of Bacteroides and Prevotella and significantly increased that of Streptococcus and Bifidobacterium.

\subsection{SCFAs}

The cecal contents of the six kinds of SCFAs (mg/g, wet weight) are shown in Figure 4. Compared with Nx + placebo, B-HD treatment tended to increase the amounts of succinic acid, propionic acid and iso-valeric acid and significantly increased the amount of lactic acid.

\section{Discussion}

Hyperphosphatemia is a widely recognized risk factor for mortality and cardiovascular disease in all stages of 

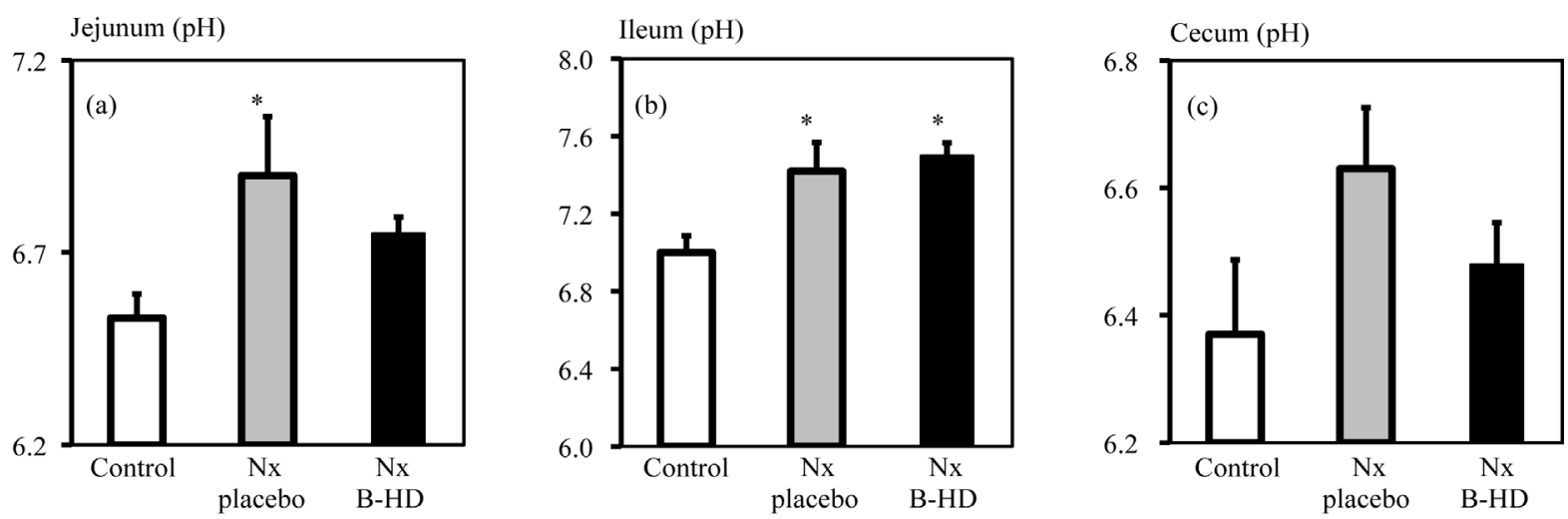

Figure 3. Effects of B-HD treatment on pH values in the contents of the jejunum (a), ileum (b) and cecum (c) in CKD rats. Control: open column. $\mathrm{Nx}+$ placebo: gray column; $\mathrm{Nx}+\mathrm{B}-\mathrm{HD}$ : filled column. ${ }^{*} \mathrm{P}<0.05$, vs Control.
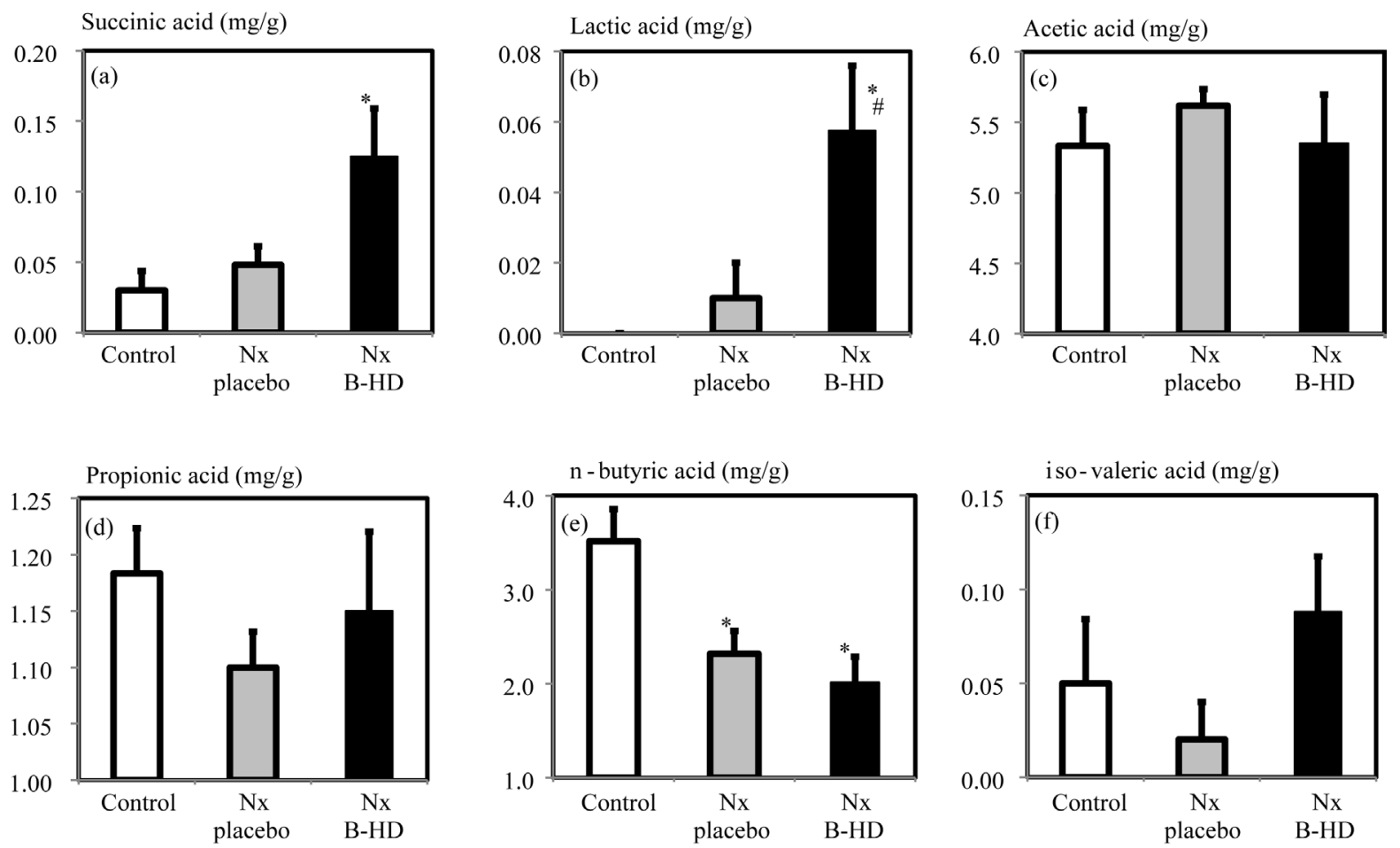

Figure 4. Effects of B-HD treatment on succinic acid (a), lactic acid (b), acetic acid (c), propionic acid (d), n-butyric acid (e) and iso-valeric acid (f) in the cecum of CKD rats. Control: open column. $\mathrm{Nx}+$ placebo: gray column; $\mathrm{Nx}+\mathrm{B}-\mathrm{HD}$ : filled column. ${ }^{*} \mathrm{P}<0.05$, vs Control. ${ }^{\#} \mathrm{P}<0.05$ vs $\mathrm{Nx}+$ placebo.

Table 1. Effects of B-HD treatment on putative copy number (\%) of each bacterium relative to total primer measurement for all test bacteria. ${ }^{\# \#} \mathrm{P}<0.01$ vs. $\mathrm{Nx}+$ placebo.

\begin{tabular}{cccc}
\hline & Control + placebo & $\mathbf{N x}+$ placebo & Nx + B-HD \\
\hline Bacteroides & $3.0 \times 10^{-6} \pm 0.93 \times 10^{-6}$ & $5.2 \times 10^{-6} \pm 0.74 \times 10^{-6}$ & $9.0 \times 10^{-6} \pm 1.6 \times 10^{-6}$ \\
Prevotella & $5.4 \times 10^{-4} \pm 1.5 \times 10^{-4}$ & $9.9 \times 10^{-4} \pm 2.5 \times 10^{-4}$ & $18.4 \times 10^{-4} \pm 8.1 \times 10^{-4}$ \\
Lactobacillus & $1.97 \pm 0.45$ & $0.85 \pm 0.10$ & $1.27 \pm 0.39$ \\
Streptococcus & $2.0 \times 10^{-3} \pm 0.60 \times 10^{-3}$ & $1.7 \times 10^{-3} \pm 0.31 \times 10^{-3}$ & $10.2 \times 10^{-3} \pm 0.20 \times 10^{-3 \# \#}$ \\
Cl. coccoides & $0.18 \pm 0.053$ & $0.11 \pm 0.013$ & $0.13 \pm 0.061$ \\
Cl. leptum & $0.93 \pm 0.14$ & $1.41 \pm 0.37$ & $0.83 \pm 0.015$ \\
Bifidobacterium & $1.2 \times 10^{-6} \pm 0.17 \times 10^{-6}$ & $2.0 \times 10^{-6} \pm 0.45 \times 10^{-6}$ & $7.9 \times 10^{-6} \pm 1.5 \times 10^{-6 \# \#}$ \\
\hline
\end{tabular}


CKD [20]. In the present study, oral administration of B-HD capsule halted the onset and progression of hyperphosphatemia in CKD rats, as previously observed in our study on HD patients [13]. The increased number of bifidobacteria was confirmed in the cecum and the concept of the gastro-resistant capsule was also verified in CKD rats. In addition, intestinal $\mathrm{pH}$ increased in $\mathrm{Nx}+$ placebo, whereas B-HD treatment tended to decrease intestinal $\mathrm{pH}$ along with increases in some SCFAs. Furthermore, serum P levels positively correlated with intestinal $\mathrm{pH}$.

Taking these results altogether, the main mechanism for the P-lowering effect of B-HD was deduced (Figure 5). The CKD condition per se alters intestinal microbial flora [7], characterized by increased aerobic and putrefactive bacteria and decreased anaerobic bacteria [5]. Aerobic and putrefactive bacteria produce ammonia from hydrolysis of urea; high levels of ammonia are responsible for elevation of intestinal $\mathrm{pH}$ which can lead to further overgrowth of aerobic and putrefactive bacteria [5] [21]. Under elevated $\mathrm{pH}$ conditions, ionization of intestinal $\mathrm{Ca}$ is decreased; this in turn increases free phosphate ion concentration through reduction of Ca phosphate crystal precipitation in the lumen. Consequently, intestinal free phosphate ions are increased and absorbed, eventually resulting in hyperphosphatemia. Thus, it is intriguing that one of the causes of hypocalcemia and hyperphosphatemia may be from an elevated intestinal $\mathrm{pH}$ due to dysbiosis in CKD. Oral administration of B-HD capsule increases not only bifidobacteria themselves but also Bacteroides, Lactobacillus and Streptococcus by probiotic effect in the intestinal tracts. Because these bacteria are known to be homo- or hetero-fermentative lactic acid bacteria, this leads to fermentation of carbohydrates to produce SCFAs, resulting in acidification of

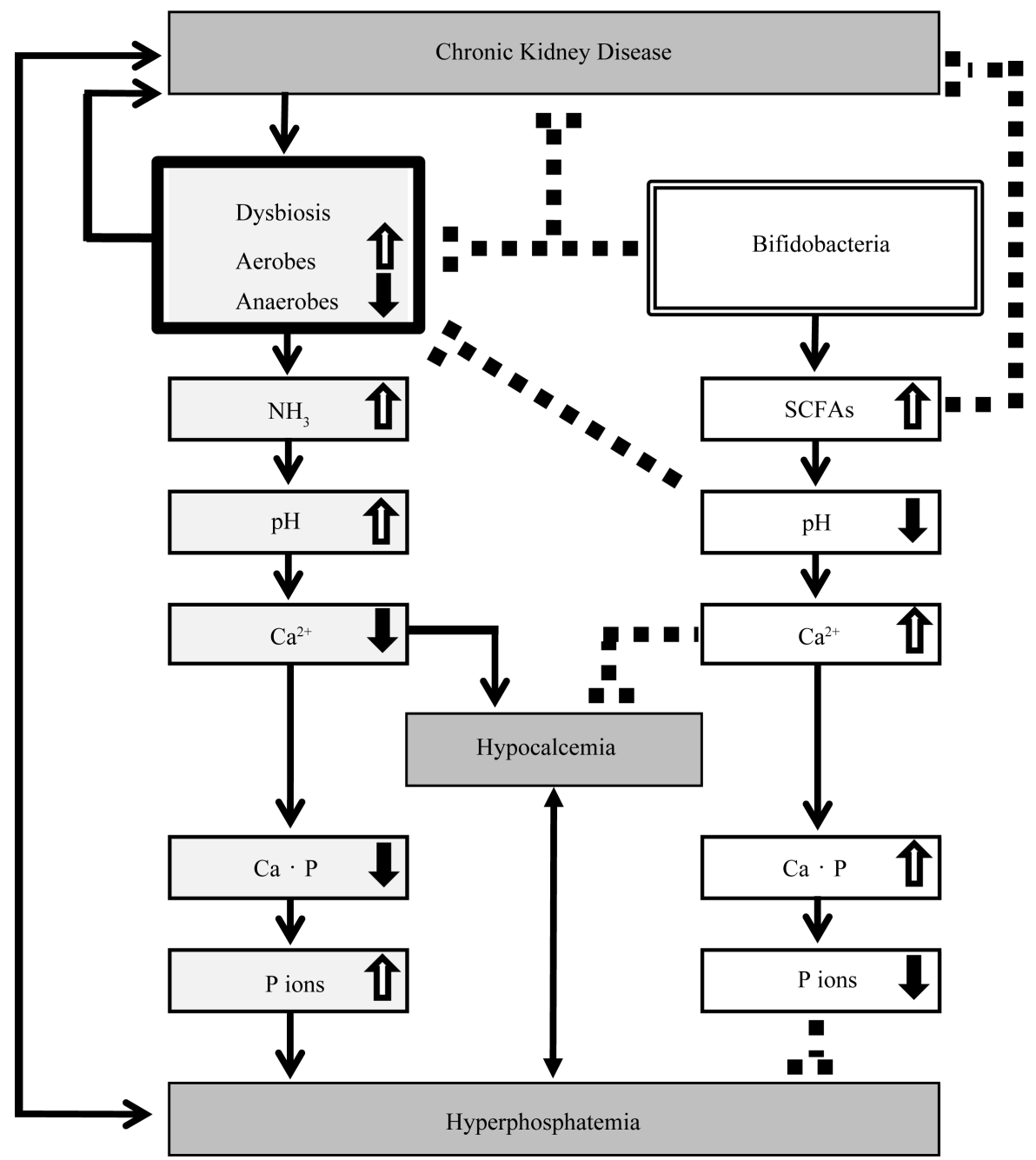

Figure 5. The mechanism for the P-lowering effect of B-HD in CKD. Ca.P, calcium phosphate; $\mathrm{P}$ ions, phosphate ions; solid line, stimulation; dashed line, inhibition. 
intestinal lumen. Lowered $\mathrm{pH}$ levels in the intestinal milieu inhibit the overgrowth of aerobic and putrefactive bacteria, thus, bifidobacteria can also cause further reduction of intestinal $\mathrm{pH}$ through this mechanism. Under decreased intestinal $\mathrm{pH}$ conditions, Ca ionization increases. As an intrinsic $\mathrm{P}$ binder, increased $\mathrm{Ca}^{2+}$ binds with free phosphate ions, resulting in Ca phosphate crystal precipitation to reduce serum $\mathrm{P}$ levels.

This mechanism is consistent with a report that $\mathrm{pH}$ level and ammonia concentration in the feces are elevated in HD patients [5]. In another study, administration of bifidobacteria decreased fecal ammonia and $\mathrm{pH}$ levels in healthy human subjects [22] and decreased cecal pH along with increased SCFAs in normal rats [15]. Furthermore, it was reported that bifidobacteria treatment increased bone Ca content and bone strength together with increased cecal propionate concentration in normal rats [23]. One of the mechanisms for the bone-effect of probiotics was considered to be due to increased mineral solubility by the production of SCFAs [24]. Indeed, the present study showed that B-HD treatment prevented reduction of serum Ca levels, whereas a significant reduction was observed in $\mathrm{Nx}+$ placebo. Increased intestinal $\mathrm{Ca}^{2+}$ caused by bifidobacteria is likely to prevent hypocalcemia.

A decrease in serum $\mathrm{P}$ levels is not likely to be associated with increased uptake of $\mathrm{P}$ into intestinal bifidobacteria and other bacteria for their proliferation because feeding of bifidobacteria did not affect the total number of bacteria, as reflected by a reduction of aerobes in the feces of healthy subjects [22]. In addition, Bifidobacterium longum, which we used in the present study, was originally isolated from human infant feces; therefore, the administered bifidobacteria could not inhabit for a certain time or proliferate in rat intestine and be eradicated by murine immune systems. Furthermore, increased fecal volume via shortening transit time was not responsible for low serum $\mathrm{P}$ levels, as evidenced by unchanged fecal dry weight between $\mathrm{Nx}+$ placebo and $\mathrm{Nx}$ + B-HD.

It is increasingly recognized that uremic toxins originating from intestinal microbial metabolism may contribute to CKD progression and complications [3] [4] [8] [9] (Figure 5). Indeed, the present study showed that B-HD treatment had a tendency towards a reno-protective effect. Therefore, we cannot exclude the probability that the P-lowering effect of B-HD was partly due to this reno-protective effect, although it was not a significant result. We have previously shown that sevelamer hydrochloride, a P binder, can protect against deterioration of renal function in CKD rats by reducing serum $\mathrm{P}$ levels [25]. Conversely, it is likely that the reno-protective effect of B-HD was partly due to its P-lowering effect. Clinical studies have also demonstrated that serum $\mathrm{P}$ levels predicted decline in renal function in the general population [26] and in CKD patients [27] [28] (Figure 5). In addition, a recent interesting study reported that intra-peritoneal injection of SCFAs (acetate, propionate and butyrate) per se prevented acute ischemic-reperfusion kidney injury in mice [29]. Thus, in the present study, the reno-protective effect could also be partly due to increased SCFAs production by bifidobacteria and other homoor hetero-fermentative lactic acid bacteria (Figure 5). Furthermore, three rats in $\mathrm{Nx}+$ placebo showed severe illness with azotemia, whereas body weight gain was steady in $\mathrm{Nx}+\mathrm{B}-\mathrm{HD}$. If we prolonged the study period, a life-extending effect may be expected from B-HD treatment. More studies are necessary to validate these hypotheses.

Our study has several limitations. First, we were unable to measure fecal excretion volume of $\mathrm{P}$ due to our technical problem. Thus, there are no data provided whether the B-HD-treated rats have higher levels of P eliminated via the feces. Second, we have no data on serum phosphaturic hormone levels including parathyroid hormone (PTH) and fibroblast growth factor-23 (FGF23) [30]. However, judging from the serum P levels, it can be presumed that B-HD treatment could inhibit or attenuate the progressive elevation of PTH and FGF23, as we showed that the elevation of PTH and FGF23 was attenuated when the serum P levels were kept in the normal range using a $\mathrm{P}$ binder in CKD rats [31]. Third, statistical significant differences were not observed in some measurements between $\mathrm{Nx}+$ placebo and $\mathrm{Nx}+\mathrm{B}-\mathrm{HD}$. The administered number of Bifidobacterium should have been increased and evaluated in more CKD rats. Finally, it will be interesting to examine the effects of B-HD treatment in normal rats.

\section{Conclusion}

Administration of bifidobacteria can decrease serum concentrations of indoxyl sulphate and $p$-cresol in HD patients [8] [32]. In addition, bifidobacteria produce vitamin B12 and folate, which can normalize serum homocysteine levels in HD patients [12]. This is an important property since most HD patients show hyperhomocysteinemia, which is a risk factor for cardiovascular disease. Although further investigation is clearly needed, the 
B-HD preparation is a simple and safe treatment option for persistent hyperphosphatemia in CKD patients. Further studies may identify additional potential benefits of B-HD treatment in CKD patients [3] [8] [10] [11].

\section{Acknowledgements}

This study was supported by a grant for pathophysiological research conference in chronic kidney disease from The Kidney Foundation, Japan (JKFB 14-29). The authors would like to thank Enago (www.enago.jp) for the English language review.

\section{References}

[1] Karlsson, F., Tremaroli, V., Nielsen, J. and Bäckhed, F. (2013) Assessing the Human Gut Microbiota in Metabolic Diseases. Diabetes, 62, 3341-3349. http://dx.doi.org/10.2337/db13-0844

[2] Festi, D., Schiumerini, R., Eusebi, L.H., Marasco, G., Taddia, M. and Colecchia, A. (2014) Gut Microbiota and Metabolic Syndrome. World Journal of Gastroenterology, 20, 16079-16094.

[3] Evenepoel, P., Meijers, B.K., Bammens, B.R. and Verbeke, K. (2009) Uremic Toxins Originating from Colonic Microbial Metabolism. Kidney International Supplements, 114, S12-S19. http://dx.doi.org/10.1038/ki.2009.402

[4] Ramezani, A. and Raj, D.S. (2014) The Gutmicrobiome, Kidneydisease, and Targeted Interventions. Journal of the American Society of Nephrology, 25, 657-670. http://dx.doi.org/10.1681/ASN.2013080905

[5] Hida, M., Aiba, Y., Sawamura, S., Suzuki, N., Satoh, T. and Koga, Y. (1996) Inhibition of the Accumulation of Uremic Toxins in the Blood and Their Precursors in the Feces after Oral Administration of Lebenin, a Lactic Acid Bacteria Preparation, to Uremic Patients Undergoing Hemodialysis. Nephron, 74, 349-355. http://dx.doi.org/10.1159/000189334

[6] Wang, I.K., Lai, H.C., Yu, C.J., Liang, C.C., Chang, C.T., Kuo, H.L., Yang, Y.F., Lin, C.C., Lin, H.H., Liu, Y.L., Chang, Y.C., Wu, Y.Y., Chen, C.H., Li, C.Y., Chuang, F.R., Huang, C.C., Lin, C.H. and Lin, H.C. (2012) Real-Time PCR Analysis of the Intestinal Microbiotas in Peritoneal Dialysis Patients. Applied and Environmental Microbiology, 78, 1107-1112. http://dx.doi.org/10.1128/AEM.05605-11

[7] Vaziri, N.D., Wong, J., Pahl, M., Piceno, Y.M., Yuan, J., DeSantis, T.Z., Ni, Z., Nguyen, T.H. and Andersen, G.L. (2013) Chronic Kidney Disease Alters Intestinal Microbial Flora. Kidney International, 83, 308-315. http://dx.doi.org/10.1038/ki.2012.345

[8] Schepers, E., Glorieux, G. and Vanholder, R. (2010) The Gut: The Forgotten Organ in Uremia? Blood Purification, 29, 130-136. http://dx.doi.org/10.1159/000245639

[9] Anders, H.J., Andersen, K. and Stecher, B. (2013) The Intestinal Microbiota, a Leaky Gut, and Abnormal Immunity in Kidney Disease. Kidney International, 83, 1010-1016. http://dx.doi.org/10.1038/ki.2012.440

[10] Lee, J.H. and O’Sullivan, D.J. (2010) Genomic Insights into Bifidobacteria. Microbiology and Molecular Biology Reviews, 74, 378-416. http://dx.doi.org/10.1128/MMBR.00004-10

[11] Leahy, S.C., Higgins, D.G., Fitzgerald, G.F. and van Sinderen, D. (2005) Getting Better with Bifidobacteria. Journal of Applied Microbiology, 98, 1303-1315. http://dx.doi.org/10.1111/j.1365-2672.2005.02600.x

[12] Taki, K., Takayama, F. and Niwa, T. (2005) Beneficial Effects of Bifidobacteria in a Gastroresistant Seamless Capsule on Hyperhomocysteinemia in Hemodialysis Patients. Journal of Renal Nutrition, 15, 77-80. http://dx.doi.org/10.1053/j.jrn.2004.09.028

[13] Ogawa, T., Shimada, M., Nagano, N., Ito, K., Ando, T., Shimomura, Y., Ando, Y. and Otsuka, K. (2012) Oral Administration of Bifidobacterium longum in a Gastro-Resistant Seamless Capsule Decreases Serum Phosphate Levels in Patients Receiving Haemodialysis. Clinical Kidney Journal, 5, 373-374. http://dx.doi.org/10.1093/ckj/sfs072

[14] Morrison, A.B. (1962) Experimentally Induced Chronic Renal Insufficiency in the Rat. Laboratory Investigation, 11, 321-332.

[15] Dinoto, A., Suksomcheep, A., Ishizuka, S., Kimura, H., Hanada, S., Kamagata, Y., Asano, K., Tomita, F. and Yokota, A. (2006) Modulation of Rat Cecal Microbiota by Administration of Raffinose and Encapsulated Bifidobacterium breve. Applied and Environmental Microbiology, 72, 784-792. http://dx.doi.org/10.1128/AEM.72.1.784-792.2006

[16] Yonei, Y., Yagi, M., Nakamura, M., Parengkuan, L., Ogura, M., Taira, T., Asano, S. and Liu, H.-H. (2013) Effects of Astaxanthin on Intestinal Microflora in Mice Fed a High-Fat Diet. Anti-Aging Medicine, 10, 77-91.

[17] Matsuki, T., Watanabe, K., Fujimoto, J., Miyamoto, Y., Takada, T., Matsumoto, K., Oyaizu, H. and Tanaka, R. (2002) Development of 16S rRNA-Gene-Targeted Group-Specific Primers for the Detection and Identification of Predominant Bacteria in Human Feces. Applied and Environmental Microbiology, 68, 5445-5451. http://dx.doi.org/10.1128/AEM.68.11.5445-5451.2002 
[18] Matsuki, T., Watanabe, K., Fujimoto, J., Takada, T. and Tanaka, R. (2004) Use of 16S rRNA Gene-Targeted GroupSpecific Primers for Real-Time PCR Analysis of Predominant Bacteria in Human Feces. Applied and Environmental Microbiology, 70, 7220-7228. http://dx.doi.org/10.1128/AEM.70.12.7220-7228.2004

[19] Endo, A., Okada, S. and Morita, H. (2007) Molecular Profiling of Lactobacillus, Streptococcus, and Bifidobacterium Species in Feces of Active Racehorses. The Journal of General and Applied Microbiology, 53, 191-200. http://dx.doi.org/10.2323/jgam.53.191

[20] Kanbay, M., Goldsmith, D., Akcay, A. and Covic, A. (2009) Phosphate-The Silent Stealthy Cardiorenal Culprit in All Stages of Chronic Kidney Disease: A Systematic Review. Blood Purification, 27, 220-230. http://dx.doi.org/10.1159/000197562

[21] Holdeman, L.V., Cato, E.P. and Moore, W.E.C. (1977) Anaerobic Laboratory Manual. 4th Edition, Anaerobe Laboratory, Virginia Polytechnic Institute and State University, Blacksburg.

[22] Benno, Y. and Mitsuoka, T. (1992) Impact of Bifidobacterium longum on Human Fecal Microflora. Microbiology and Immunology, 36, 683-694. http://dx.doi.org/10.1111/j.1348-0421.1992.tb02071.X

[23] Rodrigues, F.C., Castro, A.S., Rodrigues, V.C., Fernandes, S.A., Fontes, E.A., de Oliveira, T.T., Martino, H.S. and de Luces Fortes Ferreira, C.L. (2012) Yacon Flour and Bifidobacterium longum Modulate Bone Health in Rats. Journal of Medicinal Food, 15, 664-670. http://dx.doi.org/10.1089/jmf.2011.0296

[24] Parvaneh, K., Jamaluddin, R., Karimi, G. and Erfani, R. (2014) Effect of Probiotics Supplementation on Bone Mineral Content and Bone Mass Density. Scientific World Journal, 2014, Article ID: 595962.

[25] Nagano, N., Miyata, S., Obana, S., Kobayashi, N., Fukushima, N., Burke, S.K. and Wada, M. (2003) Sevelamer Hydrochloride, a Phosphate Binder, Protects against Deterioration of Renal Function in Rats with Progressive Chronic Renal Insufficiency. Nephrology Dialysis Transplantation, 18, 2014-2023. http://dx.doi.org/10.1093/ndt/gfg309

[26] O’Seaghdha, C.M., Hwang, S.J., Muntner, P., Melamed, M.L. and Fox, C.S. (2011) Serum Phosphorus Predicts Incident Chronic Kidney Disease and End-Stage Renal Disease. Nephrology Dialysis Transplantation, 26, 2885-2890. http://dx.doi.org/10.1093/ndt/gfq808

[27] Chue, C.D., Edwards, N.C., Davis, L.J., Steeds, R.P., Townend, J.N. and Ferro, C.J. (2011) Serum Phosphate but Not Pulse Wave Velocity Predicts Decline in Renal Function in Patients with Early Chronic Kidney Disease. Nephrology Dialysis Transplantation, 26, 2576-2582. http://dx.doi.org/10.1093/ndt/gfq787

[28] Bellasi, A., Mandreoli, M., Baldrati, L., Corradini, M., Di Nicolò, P., Malmusi, G. and Santoro, A. (2011) Chronic Kidney Disease Progression and Outcome According to Serum Phosphorus in Mild-to-Moderate Kidney Dysfunction. Clinical Journal of the American Society of Nephrology, 6, 883-891. http://dx.doi.org/10.2215/CJN.07810910

[29] Andrade-Oliveira, V., Amano, M.T., Correa-Costa, M., Castoldi, A., Felizardo, R.J., de Almeida, D.C., Bassi, E.J., Moraes-Vieira, P.M., Hiyane, M.I., Rodas, A.C., Peron, J.P., Aguiar, C.F., Reis, M.A., Ribeiro, W.R., Valduga, C.J., Curi, R., Vinolo, M.A., Ferreira, C.M. and Câmara, N.O. (2015) Gut Bacteria Products Prevent AKI Induced by Ischemia-Reperfusion. Journal of the American Society of Nephrology, in Press.

[30] Nitta, K., Nagano, N. and Tsuchiya, K. (2014) Fibroblast Growth Factor 23/Klotho Axis in Chronic Kidney Disease. Nephron Clinical Practice, 128, 1-10. http://dx.doi.org/10.1159/000365787

[31] Nagano, N., Miyata, S., Abe, M., Kobayashi, N., Wakita, S., Yamashita, T. and Wada, M. (2006) Effect of Manipulating Serum Phosphorus with Phosphate Binder on Circulating PTH and FGF23 in Renal Failure Rats. Kidney International, 69, 531-537. http://dx.doi.org/10.1038/sj.ki.5000020

[32] Takayama, F., Taki, K. and Niwa, T. (2003) Bifidobacterium in Gastro-Resistant Seamless Capsule Reduces Serum Levels of Indoxyl Sulfate in Patients on Hemodialysis. American Journal of Kidney Diseases, 41, S142-S145. http://dx.doi.org/10.1053/ajkd.2003.50104 